\title{
Peran Asupan Kalsium Terhadap Tingkat Nyeri Haid Remaja Putri
}

\author{
Ghaniy Tristianti*1 ${ }^{2}$ Zulia Setiyaningrum ${ }^{2}$ \\ 1,2 Program Studi Ilmu Gizi Universitas Muhammadiyah Surakarta \\ e-mail: ${ }^{1}$ Ghaniytristi@gmail.com; ${ }^{2}$ Setiyaningrumzulia@gmail.com
}

\begin{abstract}
ABSTRAK
Asupan kalsium yang cukup dapat menurunkan ekstabilitas neuromuskular sehingga dapat menurunkan kontraksi pada otot dan dapat mengurangi bahkan menghindari rasa nyeri pada saat haid. Berdasarkan survey pendahuluan yang dilakukan di SMK Negeri 4 Surakarta, dari 50 siswi terdapat sebanyak 84\% yang mengalami dismenorea dengan asupan kalsium yang rendah. Tujuan penelitian ini adalah untuk mengetahui hubungan asupan kalsium dengan tingkat nyeri haid pada remaja putri di SMK Negeri 4 Surakarta dengan menggunakan jenis penelitian observasional analitik dengan pendekatan crosssectional. Teknik pengambilan sampel menggunakan teknik quota sampling dengan jumlah sampel 47 siswi. Data tingkat nyeri haid diperoleh menggunakan kuesioner Numeric Rating Scale dan data asupan kalsium selama 3 bulan terakhir diperoleh menggunakan FFQ-SQ wawancara dilakukan secara daring menggunakan aplikasi Whatsapp melalui fitur chat dan vidiocall. Analisis data menggunakan uji Rank Spearman.Berdasarkan penelitian didapatkan bahwa sebagian besar responden berusia 16 tahun (85,1\%), usia menarche responden dimulai pada usia 12 tahun(51,1\%), responden mengalami haid $\leq 7$ hari $(85,1 \%)$, responden mempunyai asupan kalsium kurang(87,2\%), dan sebagian besar responden dengan asupan kalsium kurang merasakan nyeri haid dalam kategori sedang(43,9\%). Hasil uji statistik didapatkan nilai $r=-0,376$ dan $p=0,009$. Sehingga dapat disimpulkan terdapat hubungan antara asupan kalsium dengan tingkat nyeri haid pada remaja putri di SMK Negeri 4 Surakarta.
\end{abstract}

Kata Kunci : Asupan Kalsium, Dismenorea, Tingkat Nyeri Haid.

\begin{abstract}
Adequate calcium intake can reduce neuromuscular exibility so that it can reduce muscle contractions and can reduce or even avoid pain during menstruation. Based on a preliminary survey conducted at SMK Negeri 4 Surakarta, $84 \%$ of 50 students had dysmenorrhea with low calcium intake. This study aimed to determine the correlation between calcium intake and the level of menstrual pain in female students of SMK Negeri 4 Surakarta. This study was analytic observational research with a cross-sectional approach. The sampling technique used quota sampling technique with a sample size of 47 female students. Menstrual pain level data were obtained using the Numeric Rating Scale questionnaire and calcium intake data for the last 3 months were obtained using the Semi-Quantitative Food Frequency Questionnaire by means of interviews conducted online using the Whatsapp application through chat and video call features. Data analysis used Rank Spearman test. Most of the respondents were 16 years old (85.1\%), the age of the respondents menarche started at the age of $12(51.1 \%)$, respondents experienced menstruation $\leq 7$ days $(85.1 \%)$, respondents had calcium intake less $(87.2 \%)$, and most of the respondents with less calcium intake felt menstrual pain in the moderate category $(43.9 \%)$. The statistical test results obtained the value of $r=-0.376$ and $p=0.009$. There was a correlation between calcium intake and the level of menstrual pain in female students of SMK Negeri 4 Surakarta.
\end{abstract}

Keywords : Calcium intake, dysmenorrhoea, menstrual pain level 


\section{PENDAHULUAN}

Remaja adalah masa peralihan dan persiapan dari masa anak-anak menuju dewasa seperti aspek fisik, askpek psikososial dan aspek psikis [1]. Pada masa tersebut remaja akan mengalami beberapa ciri-ciri pubertas seperti menarke, perubahan psikis, pertumbuhan badan yang pesat, dan munculnya ciri-ciri kelamin sekunder [2]. Pubertas pada remaja wanita ditandai dengan menstruasi. Menstruasi adalah keluarnya darah dari rahim melalui vagina dan terjadi secara teratur setiap bulan selama masa usia subur [3].

Menstruasi pertama kali yang dialami oleh remaja disebut dengan menarke, biasanya terjadi usia 14 tahun [2].Pada masa menstruasi sering kali terjadi gejala-gejala yang timbul seperti kram pada perut bagian bawah pada saat menjelang dan selama menstruasi atau biasa disebut dengan dismenorea [4].

Terjadinya dismenorea karena adanya peningkatan kadar prostaglandin yang mengakibatkan aktivitas otot yang berlebih dan terjadinya kontraksi dinding otot hingga menyumbat pembuluh darah pada miometrium sehingga terjadi nyeri pada bagian bawah perut [3]. Dismenorea juga dapat dipengaruhi oleh kurangnya asupan nutrisi, yang mana nutrisi ini bisa didapatkan didalam makanan seperti buah dan sayuran. Nutrisi yang terdapat dalam makanan tersebut juga dapat mengurangi rasa nyeri pada saat haid contohnya seperti kalsium [5]. Penelitian yang dilakukan oleh Utami (2016) bahwa dismenorea dapat terjadi 10,33 kali lebih besar pada responden yang memiliki asupan kalsium kurang dibandingkan dengan responden yang memiliki asupan kalsium yang cukup [6].

Berdasarkan survey pendahuluan di SMK Negeri 4 Surakarta, dari 50 siswi terdapat sebanyak $84 \%$ yang mengalami dismenorea dengan asupan kalsium yang rendah. Berdasarkan masalah diatas peneliti tertarik untuk melakukan penelitian tentang hubungan asupan kalsium dengan tingkat nyeri pada remaja putri di SMK Negeri 4 Surakarta.

\section{BAHAN DAN METODE}

Jenis penelitian ini adalah penelitian observasional menggunakan desain cross- sectional. Populasi dalam penelitian ini adalah remaja putri di SMK Negeri 4 Surakarta kelas XI sejumlah 402 siswi. Cara pengambilan sampel dilakukan dengan menggunakan teknik quota sampling dengan jumlah sampel 51, namun yang terjangkau hanya 47 responden mengingat penelitian dilakukan pada pandemic covid-19. Kriteria eksklusi pada penelitian ini yaitu siswi yang mengundurkan diri menjadi responden dan siswi yang mengonsumsi obat atau jamu penghilang rasa nyeri. Data tingkat nyeri haid diperoleh dengan cara responden mengisi kuesioner Numeric Rating Scale dan data asupan kalsium selama 3 bulan terakhir diperoleh menggunakan formulir Food Frequency Semi Kuantitatif. Wawancara dilakukan dengan cara daring menggunakan aplikasi Whatsapp melalui fitur chat dan vidiocall. Uji statistik yang digunakan untuk menguji hubungan adalah uji Rank Spearman.

\section{HASIL DAN PEMBAHASAN}

Penelitian ini dilakukan pada remaja putri di SMK Negeri 4 Surakarta. Berdasarkan hasil survei pendahuluan pada 50 siswi, didapatkan hasil sebanyak $84 \%$ siswi mengalami dismenorea. Sebagian besar siswi belum memiliki pola makan yang teratur. Dari data Food Frequency Questionnaire Semi Kuantitatif diketahui bahwa beberapa siswi jarang mengkonsumsi sayuran, buah-buahan dan lebih memilih mengkonsumsi jajanan. Di sekitar sekolah terdapat beberapa pedagang yang menjual makanan seperti batagor, siomay, cakwe, maklor, es kemasan dan masih banyak lagi. 


\section{Usia Responden}

Distribusi responden menurut usia dapat dilihat pada Tabel 1.

Tabel 1.Distribusi Responden Menurut Usia.

\begin{tabular}{ccc}
\hline Usia (tahun) & $\mathbf{n}$ & \% \\
\hline 16 & 40 & 85,1 \\
17 & 7 & 14,9 \\
\hline Total & 47 & 100
\end{tabular}

Tabel 1. menunjukkan bahwa dari 47 responden, sebanyak 40 responden berusia 16 tahun $(85,1 \%)$ dan sebanyak 7 responden $(14,9 \%)$. Pada usia 15-25 tahun remaja kerap mengalami dismenorea dan akan membaik pada saat setelah melahirkan, tetapi terkadang dismenorea akan tetap berlangsung pada wanita selama usia subur [7].

Seiring bertambahnya usia, intensitas rasa nyeri haid akan semakin berkurang karena syaraf rahim juga mengalami insentivitas akibat bertambahnya usia atau penuaan, tubuh juga akan beradaptasi dengan peningkatan prostaglandin [8]. Menurut penelitian yang dilakukan oleh Yezierski (2012) bahwa terdapat hubungan antara variable usia dengan prevalensi dismenorea [9].

\section{Usia menarche responden}

Distribusi usia awal menarche dapat dilihat ditabel 2.

Tabel 2.Distribusi usia awal menarche.

\begin{tabular}{ccc}
\hline Usia awal menarche & $\mathbf{n}$ & $\mathbf{\%}$ \\
\hline 10 & 1 & 2,1 \\
11 & 11 & 23,4 \\
12 & 24 & 51,1 \\
13 & 4 & 8,5 \\
14 & 7 & 14,9 \\
\hline Total & 47 & 100 \\
\hline
\end{tabular}

Berdasarkan tabel 2. Menunjukkan bahwa sebagian besar usia menarche responden dimulai pada usia 12 tahun $(51,1 \%)$ dan jumlah responden paling sedikit pada usia menarche responden pada usia 10 tahun $(2,1 \%)$.

Menarche adalah menstruasi pertama kali yang terjadi pada wanita usia 10-16 tahun sebelum masa reproduksi. Menarche merupakan tanda bagi wanita bahwa terdapat produksi hormon hipotalamus yang akan merangsang pertumbuhan payudara, pertumbuhan rambut ketiak dan pubis, perubahan kulit, perubahan siklus dan perubahan bentuk tubuh ideal bagi wanita[10].

Usia menarche yang terlalu dini secara signifikan berhubungan dengan nyeri haid, karena fungsi organ reproduksi belum berkembang secara optimal dan sistem reproduksi juga belum siap terpapar prostaglandin[11].

\section{Lama Menstruasi Responden}

Lama menstruasi responden merupakan waktu dimana responden mengalami haid, dimulai ketika keluarnya darah sampai berhenti. Distribusi lama menstruasi responden dapat dilihat ditabel 3.

Tabel 3.Distribusi Responden Menurut Lama Menstruasi.

\begin{tabular}{ccc}
\hline Lama Menstruasi (hari) & n & \% \\
\hline$\leq 7$ & & \\
\hline 7 & 40 & 85,1 \\
\hline Total & 7 & 14,9 \\
\hline
\end{tabular}


Pada tabel 3. menunjukkan bahwa dari 47 responden terdapat $85,1 \%$ atau sebanyak 40 responden yang mengalami menstruasi dengan jangka waktu $\leq 7$ hari. Dengan rata-rata lama menstruasi 7,67 hari, menstruasi paling lama pada responden yaitu 8 hari sebanyak 8 responden dan menstruasi tersingkat yaitu 4 hari sebanyak 3 responden.

Pada umumnya lama menstruasi yaitu sekitar 3 sampai 5 hari, tetapi ada juga darah yang keluar sedikit demi sedikit di hari 1-2 dan ada juga yang sampai 7-8 hari. Menstruasi dengan durasi lebih dari normal atau lebih dari 7 hari dapat menimbulkan rasa nyeri akibat berkontraksinya uterus sehingga semakin banyak prostaglandin yang dikeluarkan. Berkontraksinya uterus yang terus menerus juga dapat mengakibatkan dismenorea karena berhentinya supply darah menuju uterus [12]. Penelitian yang dilakukan oleh Tavallaee (2011) juga membuktikan bahwa semakin lama durasi menstruasi maka akan berisiko mengalami dismenorea dengan derajat lebih tinggi [13].

\section{Kejadian Dismenorea}

Data kejadian dismenorea diperoleh dengan cara pengisian kuesioner Numeric Rating Scale dengan cara wawancara menggunakan google meet. Kuesioner terdiri dari angka 0 sampai 10 yang menggambarkan seberapa nyeri yang dirasakan. Kejadian dismenorea ini dibagi menjadi dua yaitu dismenorea untuk responden yang mengalami nyeri pada saat menstruasi dan tidak dismenorea untuk responden yang tidak mengalami nyeri pada saat menstruasi. Distribusi kejadian dismenorea dapat dilihat di Tabel 4.

Tabel 4.Distribusi Kejadian Dismenorea

\begin{tabular}{rcc}
\hline \multicolumn{1}{c}{ Kategori } & n & \% \\
\hline Dismenorea Tidak & 39 & 83 \\
dismenorea & 8 & 17 \\
\hline \multicolumn{1}{c}{ Total } & 47 & 100 \\
\hline
\end{tabular}

Pada tabel 4. didapatkan bahwa sebesar $83 \%$ responden atau sebanyak 39 responden mengalami dismenorea dan sebanyak 8 orang tidak mengalami dismenorea. Kemudian untuk mengetahui distribusi kejadian dismenorea menurut tingkat keparahan dapat dilihat di Tabel 5.

Tabel 5. Distribusi Kejadian Dismenorea Menurut Tingkat Keparahan

\begin{tabular}{lll}
\hline Kategori & $\mathbf{n}$ & \% \\
\hline Tidak nyeri Nyeri ringan & 8 & 17 \\
Nyeri sedang & 16 & 34 \\
Nyeri berat & 19 & 40,5 \\
& 4 & 8,5 \\
\hline \multicolumn{1}{c}{ Total } & 47 & 100 \\
& & \\
\hline
\end{tabular}

Di tabel 5. menunjukkan bahwa dari 47 responden mengalami dismenorea dengan tingkat nyeri yang berbeda-beda yaitu 16 nyeri ringan, nyeri sedang dan 4 nyeri berat, dan sisanya sebanyak 8 orang tidak mengalami nyeri. Responden paling sedikit yaitu mengalami dismenorea dengan tingkat nyeri berat sebanyak 4 orang atau sebesar $8,5 \%$ dan jumlah responden paling banyak mengalami dismenorea dengan tingkat nyeri sedang sebanyak 19 responden atau sebesar $40,5 \%$.

Nyeri atau sakit yang dirasakan remaja pada saat menstruasi dapat mengganggu aktivitas sehari-hari seperti menurunnya konsentrasi, mengganggu aktivitas belajar, bahkan bisa juga tidak dapat pergi sekolah[14]. 


\section{Distribusi Asupan Kalsium Responden}

Data asupan kalsium selama tiga bulan terakhir diperoleh dari form Food Frequency Semi Kuantitatif. Daftar bahan makanan yang terdapat di formulir FFQ-SQ didapatkan dari survey pendahuluan dengan cara melihat makanan apa saja yang jual di kantin dan di sekitar sekolah. Selain itu juga didapat dengan cara melihat bahan makanan apa saja yang tinggi kalsium. Setelah semua bahan makanan terkumpul lalu dimasukkan kedalam formulir FFQ- SQ untuk diisi pada saat wawancara berlangsung. Data distribusi asupan kalsium dikategorikan menjadi dua yaitu kurang untuk asupan kalsium $<1200 \mathrm{mg}$ dan baik untuk asupan kalsium $\geq 1200 \mathrm{mg}$. Data distribusi asupan kalsium dapat dilihat di tabel 6.

Tabel 6. Distribusi Asupan Kalsium Responden

\begin{tabular}{cccc}
\hline Kategori & n & \multicolumn{2}{c}{$\%$} \\
\hline \multirow{2}{*}{ Kurang Baik } & 41 & 87,2 & \\
& 6 & 12,8 & \\
\hline Total & 47 & \multicolumn{2}{c}{100} \\
\hline
\end{tabular}

Pada tabel 6. didapatkan bahwa sebanyak 47 responden terdapat $87,2 \%$ yang kekurangan asupan kalsium dan sebesar $12,8 \%$ yang asupan kalsiumnya tercukupi. Responden yang kekurangan kalsium disebabkan karena jarang mengkonsumsi makanan sumber kalsium setiap hari.

Rata-rata asupan kalsium pada 47 responden sebanyak 630,534 mg/hari dan apabila dibandingkan dengan AKG 2019, rata-rata kecukupan asupan kalsium responden sebesar 52,54\%. Dari hasil tersebut membuktik an bahwa rata-rata asupan kalsium responden masih kurang. Menurut AKG 2019 pada remaja putri usia 13-18 tahun dianjurkan untuk mengkonsumsi kalsium sebanyak $1200 \mathrm{mg} /$ hari. Tabel bahan makanan sumber kalsium yang sering dikonsumsi oleh responden dapat dilihat di tabel 7.

Tabel 7. Bahan makanan sumber kalsium yang sering dikonsumsi

\begin{tabular}{lccc}
\hline \multicolumn{1}{c}{$\begin{array}{c}\text { Bahan } \\
\text { Makanan }\end{array}$} & Frekuensi/hari Kandungan Kalsium dalam 100 gram & Konsumsi Kalsium (mg/hari) \\
\hline Nasi putih & 2.426 & $3 \mathrm{mg}$ & 21,96 \\
Telur ayam & 1.705 & $50 \mathrm{mg}$ & 18,7 \\
Teh & 0.805 & $100 \mathrm{mg}$ & 129 \\
Tahu & 0.687 & $105 \mathrm{mg}$ & 63,7 \\
Tempe & 0.657 & $93 \mathrm{mg}$ & 50,4 \\
Daging ayam & 0.375 & $13 \mathrm{mg}$ & 2,9 \\
Bayam hijau & 0.198 & $211 \mathrm{mg}$ & 27,4 \\
Susu bendera & 0.179 & $770 \mathrm{mg}$ & 36,0 \\
Cilok & 0.148 & $61 \mathrm{mg}$ & 24,2 \\
Telur bebek & 0.133 & $64 \mathrm{mg}$ & 7,94 \\
Pepaya & 0.131 & $24 \mathrm{mg}$ & 5,4 \\
Es krim & 0.116 & $116 \mathrm{mg}$ & 25 \\
Keju & 0.091 & $600 \mathrm{mg}$ & 10,88 \\
Susu milo & 0.090 & $385 \mathrm{mg}$ & 4,56 \\
Susu sapi & 0.081 & $115 \mathrm{mg}$ & 38,9 \\
\hline
\end{tabular}

Pada tabel 7. Data frekuensi/hari didapatkan dari rata-rata frekuensi konsumsi bahan makanan dari semua responden. Sedangkan data konsumsi kalsium didapatkan dari rata-rata konsumsi kalsium berdasarkan bahan makanan yang responden konsumsi. Berdasarkan tabel 7. Didapatkan bahwa sumber asupan kalsium yang paling sering dikonsumsi oleh responden yaitu nasi putih dengan frekuensi 2,426x/hari, dengan kandungan kalsium 21,96 mg/hari, dan yang kedua yaitu 
telur ayam dengan frekuensi konsumsi 1,705x/hari kandungan kalsium 18,7 gr/hari, dan sumber asupan kalsium yang paling sering dikonsumsi ketiga yaitu teh dengan frekuensi konsumsi sebanyak 0,805x/hari dengan kandungan kalsium $129 \mathrm{mg} / \mathrm{hari}$.

Sumber kalsium utama adalah susu dan hasil olahan susu, seperti keju. Ikan dimakan dengan tulang, termasuk ikan kering merupakan sumber kalsium yang baik. Serealia, kacang-kacangan tahu dan tempe, dan sayuran hijau merupakan sumber kalsium yang baik juga, tetapi bahan makanan ini mengandung banyak zat yang menghambat penyerapan kalsium seperti serat, fitat dan okasalat. Susu nonfat merupakan sumber terbaik kalsium, karena ketersediaan biologinya yang tinggi. Es krim modisco susu kedelai dengan penambahan buah dapat menjadi makanan alternatif [15]. Kebutuhan kalsium akan terpenuhi bila kita makan makanan yang seimbang setiap harinya [16]. Faktor yang dapat membantu penyerapan kalsium di dalam tubuh ialah vitamin D, laktosa, keasaman lambung, dan kebutuhan tubuh akan kalsium. Faktor penghambat penyerapan kalsium yaitu asam fitrat, asam oksalat, lemak, fisik yang kurang gerak, peningkatan motilitas saluran cerna, dan ketidakstabilan emosi [17].

Kalsium merupakan salah satu mineral yang sangat penting bagi manusia salah satunya berperan dalam pergerakan otot. Apabila kalsium dalam tubuh tidak tercukupi, maka otor sulit untuk relaksasi atau mengendur sehingga dapat mengakibatkan kekejangan pada otot [18].

\section{Hubungan Asupan Kalsium Dengan Kejadian Dismenorea}

Data asupan kalsium diperoleh dari form Food Frequency Semi Kuantitatif. Data distribusi asupan kalsium dengan tingkat nyeri haid dapat dilihat di Tabel 8.

Tabel 8. Hubungan Asupan Kalsium dengan Tingkat Nyeri Haid.

\begin{tabular}{|c|c|c|c|c|c|c|c|c|c|c|c|}
\hline \multicolumn{9}{|c|}{ Tingkat Nyeri Haid } & \multirow{2}{*}{\multicolumn{2}{|c|}{ Total }} & \multirow{3}{*}{$\begin{array}{c}P \\
\text { Value }\end{array}$} \\
\hline & \multicolumn{2}{|c|}{$\begin{array}{l}\text { Tidak } \\
\text { Nyeri }\end{array}$} & \multicolumn{2}{|c|}{$\begin{array}{c}\text { Nyeri } \\
\text { Ringan } \\
\end{array}$} & \multicolumn{2}{|c|}{$\begin{array}{c}\text { Nyeri } \\
\text { Sedang }\end{array}$} & \multicolumn{2}{|c|}{$\begin{array}{l}\text { Nyeri } \\
\text { Berat }\end{array}$} & & & \\
\hline & $\mathbf{n}$ & $\%$ & $\mathbf{n}$ & $\%$ & $\mathbf{n}$ & $\%$ & n & $\%$ & $\mathbf{n}$ & $\%$ & \\
\hline Kurang Baik & $\begin{array}{l}4 \\
4\end{array}$ & $\begin{array}{l}9,7 \\
66,6\end{array}$ & $\begin{array}{c}15 \\
1\end{array}$ & $\begin{array}{l}36,7 \\
16,6\end{array}$ & $\begin{array}{c}18 \\
1\end{array}$ & $\begin{array}{l}43,9 \\
16,6\end{array}$ & $\begin{array}{l}4 \\
0\end{array}$ & $\begin{array}{c}9,7 \\
0\end{array}$ & $\begin{array}{c}41 \\
6\end{array}$ & $\begin{array}{l}100 \\
100\end{array}$ & 0,009 \\
\hline
\end{tabular}

Berdasarkan tabel 8. Sebagian besar responden dengan asupan kalsium kurang berada dikategori nyeri sedang $(43,9 \%)$ dan dengan asupan kalsium baik terdapat 4 responden berada dikategori tidak nyeri $(66,6 \%)$.

Hasil uji statistik menggunakan uji Rank Spearman dan didapatkan hasil bahwa nilai koefisien korelasi sebesar $-0,376$ dan $p$-value sebesar 0,009 $(p<0,05)$ yang artinya terdapat hubungan signifikan antara asupan kalsium dengan tingkat nyeri haid pada remaja putri di SMK Negeri 4 Surakarta. Nilai koefisien korelasi sebesar $-0,376$ menunjukkan bahwa terdapat hubungan yang cukup antar variabel dan nilai $r$ negatif menunjukkan bahwa semakin tinggi asupan kalsium maka rasa nyeri pada saat haid semakin berkurang.

Hasil penelitian ini sejalan dengan penelitian yang dilakukan oleh Safitri dkk (2015) juga menyatakan bahwa terdapat hubungan yang signifikan antara asupan kalsium dengan kejadian dismenorea pada siswi kelas XI di SMA Negeri 2 Palu [19]. Penelitian lain juga dilakukan oleh Hidayati (2016) bahwa terdapat hubungan antara asupan kalsium dengan kejadian dismenorea pada siswi di SMK Batik 2 Surakarta. Kalsium tidak hanya dibutuhkan untuk pertumbuhan tulang, untuk remaja putri kalsium juga dibutuhkan untuk mengurangi dan menghindari rasa nyeri menjelang atau saat menstruasi [20].

Data yang didapatkan pada penelitian ini yaitu terdapat 6 responden yang memiliki asupan kalsium baik dan sebanyak 41 responden yang memiliki asupan kalsium kurang. Asupan kalsium dikatakan baik apabila $\geq 1200 \mathrm{mg} /$ hari. Sedangkan rata-rata asupan kalsium pada 47 responden yaitu sebanyak 630,534 mg/hari, apabila dibandingkan dengan AKG 2019 maka rata-rata 
kecukupan asupan kalsium responden sebesar 52,54\%. Jenis bahan makanan sumber kalsium yang sering dikonsumsi oleh responden seperti tempe, telur, daging ayam, teh, tahu, bayam, pepaya, susu ultramilk, dan cilok. Tempe merupakan bahan makanan yang paling sering dikonsumsi oleh responden dengan rata-rata konsumsi sebanyak 54,20 gr/hari dengan kandungan kalsium 50,4 mg/hari, dan yang kedua yaitu telur ayam dengan rata-rata konsumsi 37,42 gr/hari kandungan kalsium 18,7 gr/hari, dan sumber asupan kalsium yang paling sering dikonsumsi ketiga yaitu daging ayam dengan rata-rata konsumsi sebanyak 21,96 gr/hari dengan kandungan kalsium 2,9 mg/hari. Sejalan dengan penelitian yang dilakukan oleh Hidayati (2016) bahwa asupan kalsium yang kurang dipengaruhi oleh rendahnya mengkonsumsi makanan sumber kalsium. Berdasarkan hasil food frequency ditunjukkan bahwa responden jarang mengkonsumsi makanan sumber kalsium, dan makanan sumber kalsium yang paling banyak dikonsumsi oleh responden yaitu telur ayam, daging ayam dan tahu[20]. Kalsium merupakan salah satu mineral yang sangat penting bagi manusia salah satunya berperan dalam pergerakan otot. Apabila kalsium dalam tubuh tidak tercukupi, maka otor sulit untuk relaksasi atau mengendur sehingga dapat mengakibatkan kekejangan pada otot [18].

Penelitan yang dilakukan Nurmiaty (2011) hasil penelitiannya yaitu pemberian kalsium murni terbukti secara signifikan menghasilkan 50\% pengurangan gejala sindroma premenstruasi. Penurunan $100 \mathrm{mg}$ kalsium dapat menaikkan risiko mengalami PMS 2,0 kali. Asupan kalsium yang secara umum akan mengurangi nyeri selama fase menstruasi dan mengurangi retensi air selama fase premenstruasi [21]. Penelitian yang dilakukan oleh Jacobs (2000) juga mengatakan bahwa hasil dari pemberian suplemen kalsium karbonat $1200 \mathrm{mg} / \mathrm{hari}$ selama 3 siklus haid pada 472 wanita menunjukkan bahwa terbukti sebesar $48 \%$ kalsium dapat mengurangi rasa sakit menjelang haid [22]. Kalsium dapat mengurangi tekanan otot kram pada saat menstruasi. Kalsium yang masuk ke tubuh dapat memperlancar kerja otot salah satunya otot yang terdapat di uterus, tubuh yang kekurangan asupan kalsium akan lebih mudah terkena kram [23]. Dalam islam zat gizi mempunyai peran penting bagi kesehatan, setiap muslim wajib untuk memelihara kesehatan tubuhnya seperti sabda Rasul Allah SAW "Sesungguhnya badanmu mempunyai hak atas dirimu", artinya bahwa setiap menusia wajib memelihara tubuhnya sehingga dapat berfungsi dengan baik. Pada Al-Qur'an Surat 'Abasa ayat 80 tertulis bahwa "Hendaklah manusia memperhatikan makanannya", maksud dari ayat tersebut yaitu manusia dianjurkan memilih makanan yang bergizi seperti biji-bijian, sayuran, buah-buahan [24].

\section{KESIMPULAN}

Pada penelitian ini, sebagian besar responden dengan asupan kalsium kurang merasakan nyeri haid dalam kategori sedang yaitu sebesar 43,9\%, sedangkan 66,6\% responden dengan asupan kalsium baik, tidak merasakan nyeri haid . Hasil uji statistik menunjukkan bahwa terdapat hubungan asupan kalsium dengan tingkat nyeri haid pada remaja putri di SMK Negeri 4 Surakarta $(p=0,009)$. Koefisien korelasi antara asupan kalsium dengan tingkat nyeri haid berlawanan dan terdapat hubungan yang cukup antara asupan kalsium dengan tingkat nyeri haid $(r=-0,376)$.

\section{SARAN}

Responden yang memiliki asupan kalsium kurang dapat meningkatkan asupan makanan sumber kalsium agar mencukupi asupan kalsium harian sesuai dengan anjuran AKG. Perlu diadakan kerja sama dengan dinas kesehatan Surakarta untuk mengedukasi pola makan gizi seimbang dan memberikan penyuluhan mengenai mencegahan dan menguragi rasa nyeri pada saat menstruasi, terutama zat gizi apa saja yang diperlukan untuk terapi dismenorea.

\section{DAFTAR PUSTAKA}

[1] Sofia, A dan Adiyanti M.G. 2013. Hubungan Pola Asuh Otoritatif Orang Tua Dan Konformitas Teman Sebaya Terhadap Kecerdasan Moral.

[2] Anwar, M., Baziad, A., Prabowo, RP. 2011. Ilmu Kandungan. Edisi Ke-3. Jakarta: Bina Pustaka Sarwono Prawiroharjo. 
[3] Marlina, E. 2012. Pengaruh Minuman Kunyit Terhadap Tingkat Nyeri Dismenore Primer pada Remaja Putri di SMA Negeri 1 Tanjung Mutiara Kabupaten Agam. Padang. Skripsi. Universitas Andalas.

[4] Djuanda, A. 2010. Ilmu Penyakit Kulit dan Kelamin. Jakarta : Fakultas Kedokteran Universitas Indonesia.

[5] Utami, A.N.R. 2012. Faktor yang Berhubungan dengan Kejadian Dismenorea pada Remaja Putri Di SMAN 1 Kahu Kabupaten Bone. Skripsi. Fakultas Kesehatan Masyarakat UNHAS Makassar. Makassar.

[6] Utami R. D. 2016. Kejadian Dismenore Primer pada Siswi MAN 1 Kota Bandung. Politeknik Kesehatan Kemenkes Bandung.

[7] Alam, S dan Hadibroto, I. 2007. Endometriosis. Jakarta: PT. Gramedia Pustaka Utama.

[8] Okoro, R. N., Malgwi H dan Okoro G. O. 2013. Evalution of Factors that Increase the Severity of Dysmenorrhea among University Female Students in Maiduguri, North Eastern Nigeria. Journal of Allied Health Sciences and Practice 11(4): 1-10.

[9] Yezierski, R.P. 2012. The Effect of Age On Pain Sensitivity : Pre-clinical Studies,Pain Medicine 13(2): 27-36.

[10] Proverawati, A dan Siti Asfuah. 2009. Buku Ajar Gizi Untuk Kebidanan. Yogyakarta : Nuha Medika.

[11] Charu, S., Ray, A., Ray, S and George, A. T. 2012. Menstrual Characteristics and Prevalence and Effect of Dysmenorrhea on Quality of Life of Medical Students. International Journal Of Collaborative Research on Internal Medicine and Public Health 4(4): 276-294.

[12] Anurogo. 2011. Cara Jitu Mengatasi Nyeri Haid.

[13] Tavallaee, M., Michel, R. J., Stephen, J. C., Mana, B and Mahnaz, M. R. 2011. The Prevalence of Menstrual Pain and Assocoated Risk Factors among Iranian Women. Journal of Obstetrics and Gynaecology Research. 37(5): 442-451.

[14] Lestari, N.M.S.D. 2013. Pengaruh Dismenore pada Remaja. Seminar Nasional, FMIPA UNDIKSHA III Tahun 2013, Singaraja.

[15] Kumala FD, Setyaningsih S, Ratnasari D. Nilai Gizi Dan Daya Terima Es Krim Modisco Susu Kedelai dengan Penambahan Buah untuk Penanganan Anak Gizi Buruk. Jurnal Ilmiah Gizi dan Kesehatan (JIGK). 2020 Aug 31;2(01):28-37.

[16] Cakrawati, D dan Mustika N.H. 2012. Bahan Pangan, Gizi dan Kesehatan. Bandung: Alfabeta.

[17] Hardinsyah dan Supariasa. 2017. Ilmu Gizi Teori dan Aplikasi. Jakarta: EGC.

[18] Almatsier, S. 2009. Prinsip Dasar Ilmu Gizi. Jakarta: PT. Gramedia Pustaka Utama.

[19] Safitri, R., Rahman, N dan Hasanah. 2015. Hubungan Asupan Kalsium dan Aktivitas Olahraga dengan Kejadian Dismenore pada Siswi Kelas XI di SMA Negeri 2 Palu. Jurnal Kesehatan Tadulako Vol. 1 No. 1.

[20] Hidayati, K.R. 2016. Hubungan Antara Asupan Kalsium dan Asupan Zat Besi dengan Kejadian Dismenore pada Siswi di SMK Batik 2 Surakarta. Karya Tulis Ilmiah. Universitas Muhammadiyah Surakarta.

[21] Nurmiaty. 2011. Perilaku Makan dengan Kejadian Sindrom Premenstruasi pada Remaja. Berita Kedokteran Masyarakat 27(2): 75-82.

[22] Jacobs-Thys, S. 2000. Micronutrients and The Premenstrual Syndrome: The Case for Calcium. Journal American College of Nutrition, 2 (19):220-227.

[23] Hudson, T. 2007. Using Nutrition to Relieve Primary Dysminorrhea. Alternativ Complementary Therapies. Mary ann Liebert, Inc, Vol. 13: 125-128.

[24] Shobron, S., Mahasri., Sobahiya dan Syamsul, H. 2010. Studi Kemuhammadiyahan. Surakarta: LPIK-UMS. 